\title{
Rastros de maus-tratos domésticos contra as mulheres em cantigas medievais
}

\author{
Luiz Paulo Labrego de Matos ${ }^{\mathrm{i}}$
}

\begin{abstract}
RESUMO
O presente artigo tem por objetivo central analisar quatro cantigas medievais galegoportuguesas que versam sobre a violência doméstica sofrida por mulheres na sociedade lusitana da Baixa Idade Média. Para tanto, optamos por pensar o local onde as agressões ocorriam, mais especificamente, a casa medieval portuguesa, bem como, para uma melhor contextualização, as configurações da educação voltadas às mulheres e quais as suas implicações na construção da vida social das jovens. Ao fim, os poemas que nos serviram como fonte primária serão analisados, destacando o objeto de pesquisa em questão.
\end{abstract}

Palavras-chave: cantigas medievais galego-portuguesas; Trovadorismo; Portugal medieval; Literatura Portuguesa.

\begin{abstract}
Questo articolo si propone di analizzare alcune canzoni medievali galiziano-portoghesi che trattano della violenza domestica subita dalle donne nella società lusitana del Basso Medioevo. Per questo, abbiamo scelto di pensare al luogo dove si sono verificate le aggressioni piú specficamente la casa medievale portoghese. Inoltre, affinché lo studio sia meglio contestualizzato, abbiamo deciso di pensare a quali sono le impostazioni educative per le donne e quali sono le loro implicazioni nella costruzione della vita sociale di queste giovani donne. Alla fine, le poesie che ci hanno servito come fonte primaria vengono analizzate, evidenziando l'oggetto di ricerca in questione.
\end{abstract}

Parole chiave: canzoni medievali galiziano-portoghesi; trovatori; Portogallo medieval; letteratura portoghese.

\footnotetext{
${ }^{i}$ Doutor em Letras pela Universidade do Estado do Rio de Janeiro (UERJ). Técnico em Assuntos Educacionais da Faculdade de Educação da UFF. | https://orcid.org/0000-0002-4468-1085 | luizpaulolabrego@yahoo.com.br
} 
Como se sabe, as cantigas de amigo fazem parte do grupo de poemas do trovadorismo ibérico medieval e são grandes monumentos literários que servem também como testemunhos de como se vivia e de como se comportava aquela gente à época. Esses poemas são especialmente interessantes, sobretudo pela diversidade de temas abordados e por características populares bastante evidentes, refinadas pela escrita dos trovadores.

Engana-se quem pensa que o assunto da violência doméstica praticada pela mãe contra a filha será encontrado nas cantigas de escárnio e maldizer: todos os poemas que abordam essa questão são do gênero de amigo, os quais apresentam muitos traços regionais e refletem um cotidiano social rico em informações historiográficas.

A voz feminina é a marca mais emblemática desse tipo de cantiga. A moça espera por seu amado, tem encontros com ele e, algumas vezes, entrega-se aos prazeres da carne. Não existe aí, via de regra, aquele sentimento sublimado que se encontra nas cantigas de amor. Distanciando-se dos preceitos normativos da cortesia, apresentam cenas do que seria o quotidiano, podendo ser consideradas "objetivas, imagéticas, narrativas, realistas na escassa marcação concreta de tempo e espaço" (MONGELLI, 2009, p. 96).

Nas cantigas selecionadas, encontramos a jovem em desespero pela dor que sente por não poder se relacionar com o seu amigo ou com o seu namorado. Retrata-se nelas também o papel das mães na educação das donzelas, sendo essas matriarcas responsáveis por manter as filhas resguardadas, virgens e honradas face ao assédio do namorado ou do pretendente. Por isso mesmo, são descritas como as grandes agressoras das jovens, dado que, como foi dito, nesse tipo de cantigas, o amor deixa de ser sublimado e se concretiza em diversos momentos: "a posse do objeto amado deixa de ser simples anseio, aureolado de misticismo e suspiros vãos, para se tornar plena realidade" (MOISÉS, 1998, p. 236).

Vale ressaltar que, muito embora as cantigas de amigo reflitam o cotidiano daquelas pessoas e sejam consideradas mais populares e narrativas, evidentemente que não se esgotam como fontes e deixam muitas lacunas em diversos momentos. Uma dessas brechas, por exemplo, está relacionada diretamente ao tema do presente artigo. Esses poemas informam acerca da realidade de jovens abastadas e, no entanto, muito pouco encontraremos sobre o que era a vida das donzelas mais pobres e camponesas. 
Podemos propor analogias e diálogos com outras fontes, mas esse vazio deve ser levado em consideração ao se trabalhar com o tema.

\section{O LOCAL DO "CRIME"1}

Como eram as casas onde a gente lusitana vivia na Baixa Idade Média? Qual o tamanho das habitações e o que era comum encontrar dentro delas? Havia diferenças entre as casas urbanas e rurais? Essas questões veem à cabeça quando se inicia a leitura das cantigas e entra-se em contato com as primeiras informações sobre os maus-tratos domésticos.

As informações sobre as moradias são escassas. Sabemos apenas algumas características, como a média do tamanho das casas e o que nelas costumava ter. Há, ainda, mais elementos sobre as moradias urbanas do que sobre as rurais. É possível descobrir também algumas configurações arquitetônicas que havia naquela época. $\mathrm{O}$ mais interessante, certamente, é pensar como, possivelmente, se comportavam os moradores dessas habitações medievais.

As casas possuíam em média de 50 a $70 \mathrm{~m}^{2}$. Em Lisboa, por exemplo, elas mediam em torno de $40 \mathrm{~m}^{2}$. Já em Elvas, a sua extensão costumava ser de $90 \mathrm{~m}^{2}$. Normalmente, elas tinham apenas uma saída que corresponderia à porta de entrada. Apesar disso, havia uma certa preocupação com a estética de sua fachada. Basicamente, eram feitas de materiais como madeira, barro, produtos orgânicos e terra. Localizavamse junto às ruas e os cômodos mais "privados", como o quarto, eram situados na parte de trás das habitações. Desde essa época, já era comum encontrar uma espécie de "puxadinho" acoplado posteriormente à construção (CONDE, 2016, p. 68).

Havia um outro modelo de construção bastante comum chamado de "curtis". Tratava-se de sobrados que compartilhavam o mesmo pátio. Nessa área comum, os moradores costumavam guardar os seus animais e alguns objetos pessoais. A preferência por esse formato de moradia se devia ao aumento significativo do valor das terras nas grandes cidades. Vale lembrar que, em ambos os formatos de arquitetura, havia uma constante e enorme preocupação com os recorrentes incêndios que destruíam as casas. 
Sobre o mobiliário, sabe-se pouco. Via de regra, havia poucos móveis como arcas, baús e escanos. No entanto, "eventualmente, poderia haver mesas, banquetas e cadeiras de braço. Em casas mais abastadas, poderia haver roupa de cama, cobertores, colchões, almofadas, mantas, cobertores finos, cubas, vasos e outros utensílios." (CONDE, 2016, p. 60)

É curioso ressaltar que o tamanho das casas estava intrinsecamente relacionado ao constante risco de invasão árabe. Não seria interessante construir grandes moradias e ter de deixá-las para trás em caso de uma dominação moura. Portanto, a guerra contra os árabes influenciou na produção arquitetônica e urbanística de Portugal.

Assim eram as moradias portuguesas medievais. Pessoas misturadas em cômodos apertados e abafados. Casas sem quase nenhuma estrutura de saneamento e ventilação. Pais, mães e filhos convivendo com as intimidades uns dos outros. Nesse cenário era onde possivelmente ocorriam os tapas, os beliscões e as outras agressões contra as jovens moças que os trovadores cantam em seus poemas.

\section{A CONDIÇÃO FEMININA E A SUA EDUCAÇÃO}

Antes de tudo, é importante lembrar que as informações de que dispomos sobre as mulheres na Idade Média foram construídas, ao longo do tempo, por escritas masculinas, o que dificulta um pouco o trabalho historiográfico. Isso porque não há nesses documentos os traços dos anseios e das personalidades daquelas moças e daquelas senhoras sobre as quais se fala. O que há são interpretações e visões dos homens acerca da vida delas.

A vida dessas mulheres estava diretamente subordinada aos homens e muitas passavam os seus dias trancafiadas nos espaços privados como a casa ou o castelo. Desde o primeiro momento de sua infância, sua construção social visava ao casamento. Para isso, elas eram educadas e conduzidas segundo as exigências daquela sociedade patriarcal. O mais importante era as jovens conseguirem se tornar esposas exemplares e mães perfeitas.

Elas aprendiam os ofícios destinados às esposas - como coser, cozinhar, limpar a casa e as demais funções que visavam à organização do lar - e se preparavam para a conquista dos seus maridos. Obviamente que não se tratava de um jogo de sedução entre 
os amantes, como conhecemos hoje, mas de uma subordinação do corpo feminino aos interesses de seus pais (homens).

Junto à construção da esposa perfeita, estava a da mãe ideal. As jovens desde muito novas eram empurradas involuntariamente para a maternidade. Caberia a elas passar à frente o legado e a história de suas famílias. Por isso, era importante que as moças fossem grandes procriadores e excelentes mães. Em uma sociedade baseada em vínculos sanguíneos, para a sustentação do poder nobiliárquico, era fundamental a procriação. Sendo assim, a principal função da mulher naquela sociedade era reproduzir. Tanto que uma pessoa infértil era repudiada como esposa (OLIVEIRA, 2016, p. 309). Ter um elevado número de filhos era mostrar o seu talento e a benção divina sobre a sua vida. Essas eram as esposas benquistas pelas comunidades lusitanas. Porém, além da infertilidade natural de algumas jovens e de alguns jovens devido a fatores como a má alimentação e a pouca idade das noivas, vale lembrar que muitos abortos espontâneos ocorriam por conta da proximidade de parentesco dos casais.

Para ajudar na construção de figuras perfeitas como mães e esposas, era comum encontrarmos todo um imaginário simbólico voltado para a inserção das meninas em um mundo doméstico. Por mais atual que nos possa parecer, à época medieval, já havia, por exemplo, diversos brinquedos que inseriam as raparigas no universo das tarefas domésticas e da maternidade.

\footnotetext{
Nas louças, as meninas imitavam os gestos culinários das mães, ao mesmo tempo que recebem exemplos e hipotéticos conselhos. Com as bonecas, ensaiam, à luz dos modelos maternos familiarmente observados e comentados, os modos, atitudes e cuidados a ter com os seus futuros filhos. (OLIVEIRA, 2016, p. 311)
}

A casa era o lugar das mulheres por excelência. Passavam seus dias ocupadas com tarefas repetitivas e enfadonhas. Por outro lado, eram elas as responsáveis pela administração do lar e de algumas atividades comerciais de suas famílias. Engana-se quem pensa que as mulheres não participavam do comércio local. Há inúmeros relatos em que encontramos figuras femininas responsáveis pela troca e pela venda de produtos produzidos em suas terras. Na verdade, "a grande maioria das mulheres, para além das atividades domésticas e do tratamento dos filhos, exerce ainda outro tipo de atividade, dentro ou fora do domicílio, para que o agregado familiar possa subsistir" (OLIVEIRA, 2016, p. 308). 
Um dos motivos desse enclausuramento feminino era manter essas "criaturas inferiores" (OLIVEIRA, 2015, p. 51) sob o domínio dos homens. As mulheres eram consideradas um sexo frágil e que facilmente cederiam às tentações mundanas. A primeira delas - Eva - era um bom exemplo de perversão e da instabilidade. A responsável por dar o fruto proibido ao seu companheiro mostrava os perigos de se deixar uma mulher em liberdade. Dessa forma, era fundamental que todas estivessem sob a vigia constante dos homens da família. Por isso mesmo, até as atividades pelas quais eram responsáveis, como a educação dos filhos e a administração do lar, subordinavam-se à supervisão masculina.

\footnotetext{
As raparigas deviam, pois, permanecer em casa, bem resguardadas dos olhares masculinos. Debruçar-se da janela era já sair, pois refletia a condenada possibilidade de se abandonar ao impulso de se vaguear pela sociedade e pelo mundo dos homens, pondo em acusa o pudor e a honra que deviam pautar o comportamento ideal das jovens donzelas. (OLIVEIRA, 2015, p. 51)
}

Especificamente quanto à educação, ela caberia à mulher nos primeiros anos de vida dos filhos e das filhas. Certamente muitas se pautavam nos manuais medievais sobre o tema. Neles havia a recomendação de aproveitar todo tempo livre para difundir a fé cristã para os filhos. Assim, ao ensinar a cozinhar, a coser e a bordar, as mães deveriam sempre encaixar questões de fé no aprendizado que estava sendo passado às filhas.

No entanto, com o alto índice de analfabetismo e a baixa circulação das obras escritas, muitas mulheres nem chegariam a ter contato com esses livros. No mais, sendo eles escritos por clérigos, o que sempre era sugerido como elemento primordial para o aprendizado das crianças era a fé cristã. Nada muito distante do que já perpassava as mentes e as preocupações dos pais à época. Além disso, as recomendações ali descritas serviriam como um modelo de educação a ser seguido, o que não necessariamente acontecia. Pelo contrário, pela dificuldade de acesso às obras, a vida seguia, muita das vezes, sem ter em conta tais diretrizes religiosas.

Se, por um lado, a educação dos meninos era voltada para a construção de homens fortes e preparados para a vida externa, a das meninas privava-as cada vez mais da vida pública. Os pais deveriam evitar que suas filhas participassem de qualquer atividade exterior à casa, sobretudo a partir dos doze anos de idade até a sua ida para a 
casa do marido. Assim, deveriam "cessar os passeios, as brincadeiras fora do lar e até as conversas privadas com as amigas" (OLIVEIRA, 2015, p. 51), tudo para evitar a perda do pudor natural das jovens e, consequentemente, da sua virgindade. Até mesmo as festas e as cerimônias religiosas deveriam ser evitadas, tendo em vista que muitas trocas de olhares ocorriam nesses lugares sagrados (OLIVEIRA, 2015).

As moças poderiam aprender a ler e a escrever. No entanto, caberia às mães ensinar tal habilidade. Por isso mesmo, muitas não chegariam a praticar a leitura ou a escrita, já que as responsáveis pelo ensinamento costumavam ser analfabetas. Por outro lado, quando conseguiam ter acesso a esse tipo de aprendizagem, ele deveria ser limitado e restrito a atividades de escrita e de leitura básicas do dia a dia, não sendo nem de longe esperado que essas jovens se tornassem grandes escritoras ou leitoras assíduas.

Sobre as jovens nobres, sabemos que eram também preparadas para o casamento e para a maternidade. Por isso, desde muito jovens eram iniciadas nas tarefas do lar para que se tornassem esposas ideais. Além disso, aprendiam a ler, a apreciar música e a se portar com uma pessoa da nobreza. Deveriam saber como beber, como falar e como se vestir para agradarem os seus maridos e os seus pais.

A educação das crianças pobres não deixou muitos rastros para a História. Certamente, meninos e meninas das famílias menos abastadas não eram inseridos na cultura do letramento como mais frequentemente acontecia com os nobres. Isso porque não haveria quem lhes ensinasse a ler e a escrever e aquele tipo de conhecimento nem mesmo teria alguma praticidade no seu cotidiano. Ademais, "as crianças inseriam-se desde muito cedo no mundo do trabalho rural, artesanal e dos serviços, fornecendo um suplemento de mão-de-obra precioso à sua família" (OLIVEIRA, 2015, p. 64-65). As jovens dessa categoria social, além de se transformarem em boas esposas e exemplares mães, elas precisavam ajudar na sua sobrevivência e na de seus familiares, desde sempre. Nesse sentido, não partilhavam do universo lúdico destinado às meninas nobres e acabavam por aprender empiricamente no correr dos dias.

Para as jovens de família abastada, ainda havia a possibilidade de se retirarem para os mosteiros femininos. Aliás, esse foi um fenômeno que ocorreu muito, sobretudo a partir do século XIII. Muitas moças acabavam por escolher a vida religiosa para fugirem de casamentos arranjados e infelizes. Seu destino era principalmente os mosteiros da Ordem Cisterciense. 
Saltemos alguns anos de vida dessas jovens tratadas até aqui e pensemos em qual tipo de mãe era comum encontrarmos em Portugal na baixa Idade Média. De fato, as mulheres conseguiam se tornar exemplos de maternidade? A violência sobre a qual cantam os trovadores nos poemas selecionados era praticada por quem?

Dizia o ditado medieval: "dai-me mãe acautelada e eu vos darei filha segura" (OLIVEIRA, 2015, p. 66). O dito popular reflete muito do imaginário da gente. Nele é evidente a responsabilidade da mulher sobre a criação da filha. Além de cuidar dos afazeres domésticos, as mães deveriam ensinar a fé cristã e os costumes familiares para as suas meninas. Não muito diferente do que encontramos hoje aqui em nosso país. Eram jornadas duplas e recaía sobre a mãe qualquer fracasso que implicasse perda da virgindade ou qualquer outro desvio moral praticado pelas moças.

\footnotetext{
Para além do ensino da fé e da leitura, competia ainda à mãe medieval um papel importante na educação doméstica das filhas, transmitindo-lhe as qualidades e os saberes necessários ao desempenho das suas futuras funções de esposas e de mães. [...] a educação doméstica das filhas ainda compreendia o ensino e o treino das artes da costura e da tecelagem. (OLIVEIRA, 2015, p. 68)
}

O medo e o desespero de muitas mães em verem a honra de suas filhas - e consequentemente a de toda família - manchada pela perda da virgindade ou pela fuga em nome do amor pelo amigo deve ter contribuído em muito para os casos de maustratos domésticos encontrados nas cantigas medievais galego-portuguesas. Aliás, a agressão física contra os filhos não parece ter sido algo muito esporádico. Há relatos diversos em que são narradas histórias de violência, algumas até bastante graves, contra moças e moços. Tanto é que há alguns manuais de ensino da época que preconizavam o fim dos castigos corporais, sobretudo contra as crianças (OLIVEIRA, 2015).

Esse era o contexto social em que estavam inseridas as mães e as filhas de que tratam as cantigas selecionadas. Longe de ser um mapa completo da diversidade de relações que certamente existiam em Portugal à época, aqui nos propusemos a tão somente esboçar alguns traços característicos que marcavam a condição feminina na baixa Idade Média lusitana.

\section{AS "TESTEMUNHAS" E AS "PROVAS"}


Encontraremos nas cantigas selecionadas um breve retrato do que poderia ser a vida doméstica de algumas mulheres. Não há aqui nenhuma pretensão de esgotar o debate acerca do tema. Há apenas o intuito de mostrar como poderia ser difícil a realidade de muitas jovens à época. Para resumir a condição feminina medieval e a sua relação com alguns poemas trovadorescos, citamos desde já a professora Ana Rodrigues Oliveira para, logo em seguida, analisarmos o que alguns trovadores cantaram sobre esse universo.

\begin{abstract}
A mulher, ser fraco e instável que se tornava necessário resguardar e controlar, refluiu para o privado afastando-se da História. É certo que aumentou o caudal de textos que a ela se reportavam. Mas esse aumento verificava-se sobretudo do lado da literatura, com a construção de novos imaginários criados para fazer frente à sua nova situação. $\mathrm{O}$ chamamento trovadoresco e a imagem da senhora que, dominadora, comandava a relação amorosa, resultavam precisamente da sua saída de cena. E as biografias ou hagiografias construíam retratos exemplares, mais sintonizados com comportamentos modelo e aptos a influenciar novas gerações de leitores e ouvintes. Paradoxalmente, quando a mulher parecia estar mais presente, perdíamos o seu rastro no cotidiano. O que não deixa de ter incidências quanto ao conhecimento que podemos ter das suas atividades no campo, no paço ou na cidade. (OLIVEIRA, 2016, p. 307)
\end{abstract}

No que diz respeito à forma, todos os quatro poemas selecionados são cantigas de amigo e possuem cobras singulares e um refrão, sendo a cantiga de autoria de Nuno Peres Sandeu de modo dialogado.

A primeira cantiga ${ }^{3}$, a seguir transcrita, é de autoria de Vasco Rodrigues de Calvelo. Sabe-se muito pouco sobre a vida desse poeta. De certo, era português e originário de uma pequena nobreza da região que dá origem ao seu segundo sobrenome: Calvelo (LOPES; FERREIRA ET AL, 2002).

\author{
Quanto durou este dia, \\ mia madre, mal me trouxestes \\ e muito mal mi fezestes; \\ mais sobr' aquesta perfia \\ será hoj' aqui comigo \\ mandado do meu amigo. \\ Mal me trouxestes, sem falha, \\ e nom há rem que detenha \\ meu amigo que nom venha, \\ mia madre; se Deus mi valha, \\ será hoj' aqui comigo \\ mandado do meu amigo.
}




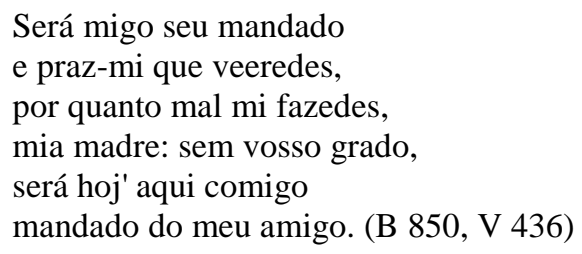

Nos versos do trovador acima cantados, encontramos, logo na primeira estrofe, uma dona reclamando da falta de compaixão de sua mãe e dos maus-tratos sofridos por conta do seu amor pelo amigo. Apesar da resistência da matriarca em aceitar o relacionamento, a jovem afirma que receberá notícias de seu amado ainda naquele dia.

$\mathrm{Na}$ estrofe seguinte, a jovem reafirma que a violência de sua mãe não impedirá que ela receba mensagem de seu amigo. Na última parte, garante que todo mal que a sua responsável fez contra ela não evitará o prazer que a moça terá de receber novidades de seu amado. Vale pensar que essas tais notícias, as que a menina se refere, podem ser, na verdade, um encontro a ser marcado pelos dois.

Fica evidente o zelo da mãe com a filha. Ela recusa pactuar com tal atitude, temendo exatamente que a menina se entregue ao seu amado. Como dito anteriormente, o medo da sua genitora estava diretamente relacionado à perda da virgindade e, consequentemente, à da honra da donzela. Para evitar que a filha cometa esses desvarios, a mãe castiga-a fisicamente.

A seguir, transcrevemos o segundo poema selecionado, de autoria de outro trovador português, João Soares Coelho, descendente, por via bastarda, de Egas Moniz e dos senhores de Ribadouro e que, provavelmente, teria nascido nos primeiros anos da segunda década do século XIII e criado em Cinfães (LOPES; FERREIRA ET AL, 2002).

\footnotetext{
Amigo, queixum' havedes de mi, que nom falo vosco, e, quant'eu de vós conhosco, nulha parte nom sabedes de quam muito mal, amigo, sofro se falardes migo.

Nem de com' ameaçada fui um dia pola ida que a vós fui e ferida, nom sabedes vós en nada de quam muito mal, amigo, sofro se falardes migo.
} 


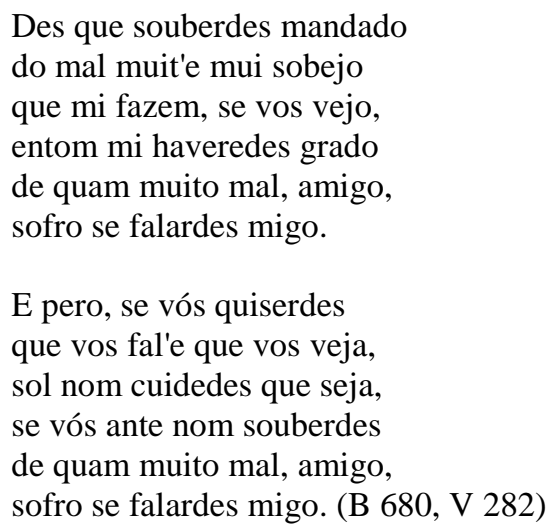

Nessa composição, vemos as queixas da jovem amante em relação à insatisfação de seu amigo. Ela esclarece ao amado que não pode e não consegue ter com ele porque seria severamente castigada caso o encontrasse. Se, por um lado, ele reclama da falta de contato com a amada, por outro, ela justifica que essa ausência se deve exatamente aos males que sofria quando sabiam de qualquer aproximação entre dois.

Já na segunda estrofe, ela argumenta que ele não sabe, mas que foi agredida por eles terem se encontrado. E o refrão retoma a ideia de que o moço não sabe de quanto mal sofre a jovem donzela quando fala com ele. Certamente que, quando souber da violência a que está submetida a sua amada por causa do seu amor, agradecer-lhe-á por tamanha amizade.

Por fim, a jovem não descarta a possibilidade de se encontrar com o amigo, mas, antes de tudo, é preciso que ele tenha consciência do sofrimento pelo qual ela passa para continuar vivendo esse amor. Quanto ao autor das agressões, não fica claro quem era. No entanto, vale lembrar que:

Embora a cantiga não especifique quem é o/a autor/a das agressões, nalgumas outras cantigas de amigo que aludem a situações semelhantes, é sempre a mãe que bate na filha. De resto, no universo, geralmente entendido como idílico, das cantigas de amigo este grupo de cantigas abre-nos uma janela para as relações familiares na Idade Média, mostrando-nos também como muitos trovadores são observadores atentos (quando não críticos) do mundo que os rodeia. (LOPES; FERREIRA ET AL, 2002)

O terceiro trovador selecionado, Nuno Peres Sandeu, não deixou muitas informações acerca da sua biografia. Acredita-se que se tratava de um poeta português. Nada além disso podemos afirmar. Passemos ao poema: 


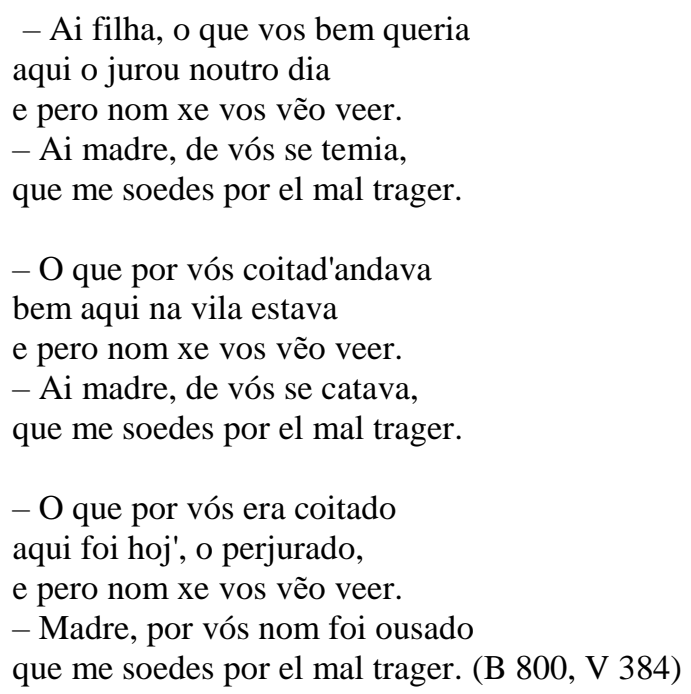

Vemos que esse poema, diferentemente dos demais, é composto em forma de diálogo entre a mãe e a filha. A genitora tenta convencer a jovem sobre as verdadeiras intenções do seu amado. Segundo ela, o rapaz não se importa com a donzela como a menina pensava. Tenta jogar a filha contra o moço, mas a jovem contra-argumenta que ele só não foi ter com ela porque sabia dos maus-tratos domésticos que sofreria caso eles se encontrassem.

Mais uma vez, fica clara a relação entre a violência doméstica e o medo de haver algum contato amoroso da jovem com o amado. A figura da mulher como responsável pela educação e pelo cuidado das moças se evidencia em mais uma cantiga.

A seguir, trataremos da cantiga do galego João Lopes de Ulhoa, trovador e cavaleiro de uma ordem militar. Sabemos até mesmo o nome de seus pais: Lopo Rodrigues de Ulhoa e Maria Fernandes Batissela. Não temos como precisar a sua data de nascimento e nem tampouco de falecimento. Afirmamos apenas que viveu no século XIII e que teve passagens por Portugal, onde teria se casado com Sancha Lourenço Taveira (LOPES; FERREIRA ET AL, 2002).

\footnotetext{
Que mi queredes, ai madr'e senhor? Ca nom hei eu no mund'outro sabor se nom catar ali per u há viir meu amigo, por que moiro d'amor, e nom poss' end'eu os olhos partir.

Já me feristes cem vezes por en [e] eu, mia madre, nom hei outro bem se nom catar ali per u há viir meu amigo, por que perço o sem
} 


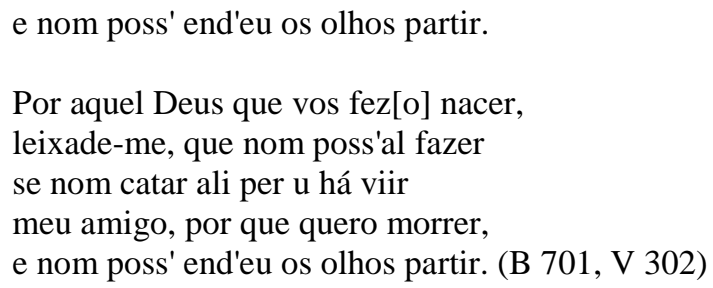

Nessa cantiga, uma jovem argumenta com a sua mãe que no mundo não há nada que lhe dê mais prazer do que aguardar a vinda de seu amigo. Continua afirmando que, por mais que a genitora já lhe tenha espancado mais de cem vezes, ainda assim ela aguardará a chegada de seu amado. A donzela roga a sua mãe, evocando Deus, que a deixe esperar por seu amigo em paz.

Sendo assim, por mais que a mãe tenha a pretensão de retirar de sua filha a vontade de aguardar pela vinda do amigo, a donzela insiste em desobedecer às ordens de sua responsável, o que, provavelmente, tenha gerado as agressões que a menina sofrera.

\section{CONCLUSÃO}

Pelo pouco que se foi debatido no presente trabalho, podemos perceber que a vida das mulheres na baixa Idade Média portuguesa não era das mais fáceis. Sobre as mães, recaía a responsabilidade de cuidar da virgindade e da honra de suas filhas. Às moças, não era dado o direito de decidir sobre sua vida amorosa e nem tampouco acerca da sua sexualidade. Tempos complicados para ser mulher.

Nos poemas selecionados para ilustrar a teoria aventada, encontramos os trovadores tratando dessa violência que incidia sobre as jovens moças. E, por mais que o canto seja medieval, mais uma vez podemos verificar que traços daqueles séculos ainda ecoam na nossa sociedade atual.

\section{Referências}

CONDE, Silvio. A casa. In: MATTOSO, José. História da vida privada em Portugal: a Idade Média. Lisboa: Círculo de Leitores, 2016. p. 54-77. 
LOPES, Graça Videira; FERREIRA, Manuel Pedro et al. Cantigas medievais galegoportuguesas [base de dados on-line], 2002. Lisboa: Instituto de Estudos Medievais, FCSH/NOVA.

MOISÉS, Massaud. Fernando Pessoa: o espelho e a esfinge. São Paulo: Cultrix, 1998.

MONGELLI, Lênia Márcia. Fremosos cantares: antologia da lírica medieval galegoportuguesa. São Paulo: Martins Fontes, 2009.

OLIVEIRA, Ana Rodrigues. O dia-a-dia em Portugal na Idade Média. Lisboa: A esfera dos livros, 2015.

OLIVEIRA, Ana Rodrigues; OLIVEIRA, António Resende de. CONDE, Silvio. A mulher. In: MATTOSO, José. História da vida privada em Portugal: a Idade Média. Lisboa: Círculo de Leitores, 2016. p. 300-323.

Recebido em: 04/06/2020

Aceito em: 16/07/2020

\footnotetext{
${ }^{1}$ Obviamente que essas agressões praticadas pelas mães contra as jovens não eram tidas como crimes e nem eram muito incomuns. A bem da verdade, o próprio contexto social medieval nos mostra uma sociedade inserida na violência.

${ }^{2}$ Evidente que o conceito de privacidade na Idade Média era muito diverso daquele que temos hoje. Quando dizemos privado, estamos nos referindo aos cômodos como o quarto e o banheiro.

${ }^{3}$ Todas as cantigas foram retiradas de LOPES, Graça Videira; FERREIRA, Manuel Pedro et al. Cantigas medievais galego-Portuguesas [base de dados on-line], 2002. Lisboa: Instituto de Estudos Medievais, FCSH/NOVA. Disponível em: http://cantigas.fcsh.unl.pt\&gt. Ao final de cada poema, haverá a sua localização nos Cancioneiros. Assim, fica determinado que B refere-se ao cancioneiro da Biblioteca Nacional e V ao da Vaticana.
} 